\title{
Development of a Novel Film Based on Bacterial Nanocellulose Reinforced Gelatin/Guar Gum Containing Honey for Wound Healing Applications
}

Parinaz Nezhadmokhtari ( $\sim$ Parinazmokhtari@gmail.com )

Tabriz University of Medical Sciences

Nahideh Asadi

Tabriz University of Medical Sciences

Marjan Ghorbani

Tabriz University of Medical Sciences

Azizeh Rahmani Del Bakhshayesh

Tabriz University of Medical Sciences

Morteza Milani

Tabriz University of Medical Sciences

Abolfazl Akbarzadeh

Tabriz University of Medical Sciences

\section{Research Article}

Keywords: Bacterial nanocellulose, Honey, Guar gum, Antibacterial films, Wound healing.

Posted Date: November 18th, 2021

DOI: https://doi.org/10.21203/rs.3.rs-1051347/v1

License: () (1) This work is licensed under a Creative Commons Attribution 4.0 International License.

Read Full License 


\section{Abstract}

Bacterial nanocellulose (BNC) is a type of 3-dimensionally structured polymer gel produced by Acetobacter that has recently attracted increased interest in wound healing concerns. To produce an effective antibacterial wound dressing, researchers investigated the manufacturing and structural features of honey-infused BNC reinforced gelatin/aldehyde-modified Guar gum films (H/BNC/Ge/AD-GG). Fourier transform infrared spectroscopy (FTIR), scanning electron microscopy (SEM), thermogravimetric analysis (TGA), mechanical characteristics, water solubility, and degradability were all used to assess the produced films. In addition, the influence of honey addition on the produced films' various properties has been examined. Antibacterial activity, better degradation capability, improved mechanical qualities, and excellent cell adhesion and proliferation by $\mathrm{NIH}-3 \mathrm{~T} 3$ fibroblast cells were among the outcomes. The cytotoxicity assay in vitro revealed good cytocompatibility. As a result of the findings, the produced $\mathrm{H} / \mathrm{BNC} / \mathrm{Ge} / \mathrm{AD}-\mathrm{GG}$ films appear to have a high potential for antibacterial wound dressing applications.

\section{Introduction}

Wound healing is a complex and difficult process that has been studied in various ways (Rahmani Del Bakhshayesh et al. 2018a; Tottoli et al. 2020). Among the different methods, wound dressing approaches has become very important all over the world due to accelerating and facilitating skin regeneration (Maver et al. 2015; Hsu et al. 2019). In recent years, various types of modern wound dressings have been successfully marketed in various shapes such as gels, thin-film, or foams based on different biocompatible materials (Yaghoobi et al. 2019). Modern wound dressings have excellent moisturizing properties on the wound surface, oxygen permeability, absorption of secretions, and drug loading capacity (Obagi et al. 2019). In this regard, many studies have shown that bioactive polymers due to their antimicrobial properties, modulating the immune system, cell proliferation, and angiogenesis could be useful in the healing of wounds and are a great opportunity to protect fragile skin (Rahmani Del Bakhshayesh et al. 2018b; Sahana and Rekha 2018; Asadi et al. 2021). On the other hand, the bioactive properties of biopolymers along with technological advances in materials science are also effective in wound care and provide new therapeutic and repair pathways. Nature-derived biopolymers are important in the production of wound dressings with unique attributes for various purposes (McClements and Gumus 2016; Suarato et al. 2018). Several techniques such as lyophilization (Kucharska et al. 2008), solvent casting (Bierhalz and Moraes 2016), salt washing (Poonguzhali et al. 2018), and electrospinning (Trinca et al. 2017) have been used to fabricate porous and dense biopolymer films and membranes that suitable for wound dressing applications. On the other hand, biopolymers are used alone or in combination with other polymers as composites or multilayer systems to make wound dressings (Pacheco et al. 2020). Also, biopolymers, by combining with bioactive substances such as plant-derived compounds, antibiotics, anti-inflammatory, antimicrobial and anti-neoplastic agents, can act as drug delivery systems to further improve therapeutic and restorative functions (Taghipour et al. 2019; Bombaldi de Souza et al. 2020; Doozandeh et al. 2020; Rahmani Del Bakhshayesh et al. 2020; Tan et al. 2021). 
Bacterial nanocellulose (BNC) is a suitable biological material that meets all the requirements of modern wound dressings (Bielecki et al. 2016). Conventional cellulose dressings are 100 times thicker than BNC fibers, which makes BNC fibers a completely biocompatible hydropolymer that is also mechanically stable. BNC fibers also act as an obstacle against microbial contamination and are therefore useful in making high-performance wound dressings (Moritz et al. 2014; dos Santos et al. 2018). Wound dressings based on BNC have also been shown to induce gas exchange, moisten the wound environment, and absorb secretions (Fu et al. 2013). Suprasorb ${ }^{\circ} \mathrm{X}+\mathrm{PHMB}$ is a commercial BNC product containing polyhexanide marketed as antiseptic wound dressing for different wounds with different amounts of exudation (Kingley et al. 2009; Dissemond et al. 2010). Guar gum (GG), on the other hand, a biopolymer derived from the seeds of Cyamopsis tetragonoloba has no toxic effect (Ghosh Auddy et al. 2013). Due to its high biodegradability and biocompatibility, this natural material is applied in many biological processes (Thakur et al. 2009), especially as a bioabsorbable material for wound dressing (Bajpai and Raj 2021). In order to expand the use of GG in various fields, its chemical properties can be easily modified by surface functionalization (Das et al. 2011; Prabaharan 2011; Bandyopadhyay et al. 2019; George et al. 2019). GG is highly soluble in water owing to the presence of more hydroxyl groups in its structure, and this complete solubility can be a disadvantage (Coviello et al. 2007; Daud et al. 2021). There are different methods such as using crosslinkers especially glutaraldehyde and 1-ethyl-3-(3dimethylaminopropyl) carbodiimide hydrochloride (EDC) to reduce the solubility of GG and improve its thermal and mechanical properties (Banegas et al. 2013; Ghosh et al. 2018). Gelatin is another biopolymer that can enhance the migration of keratinocytes, which are vital for skin repair, and has also a strong effect on the proliferative behavior of fibroblasts (Nezhad-Mokhtari et al. 2018, 2019; Lin et al. 2021). Various gelatin dressings in the form of hydrogel-like membranes (hydrofilms) (Mishra et al. 2011; Garcia-Orue et al. 2019; Alibolandi et al. 2021), spongy structures (Kanokpanont et al. 2012; Das et al. 2021), and electrospun matrices (Chen et al. 2016; Samadian et al. 2020) have been reported for use in repairing skin lesions and severe burns. Due to the rapidly solubility of the gelatin in aqueous media, cross-linkers, such as glutaraldehyde (Ye et al. 2019) and genipine (Chang et al. 2003; llkar Erdagi et al. 2020), are commonly used to circumvent this undesirable aspect, eventually creating distinct structures in terms of different physical, mechanical, chemical, and biological properties (Morsy et al. 2017; Kenawy et al. 2019). It has been reported that the bioactivity of gelatin films can be enhanced through using a combination of bioactive agents such as vitamins A and E (Li et al. 2016), vitamin B12 (Farzanfar et al. 2020), growth factors, especially epidermal growth factor (EGF) (Tanaka et al. 2005), Propolis (Ceylan 2021), ZnO particles (Chen et al. 2019), Thyme oil (Kavoosi et al. 2013), and Honey (Wang et al. 2012) in gelatin formulations, thereby improving their performance as a superficial or deep wound dressing. Honey, which has been used for centuries to heal diverse wounds and burns (Yilmaz and Aygin 2020), has been used and evaluated in various studies as a natural substance in wound dressings (Tavakoli and Tang 2017; Tang et al. 2019; Abou Zekry et al. 2020; Nezhad-Mokhtari et al. 2021). Honey is a safe natural substance that is effective against several human pathogens (Khalil et al. 2014) and also reduces the odor of abscesses (Prasetyo and Safitri 2018). More importantly, it has an effect on angiogenesis and helps to form granular tissue and regenerate epithelium (Chaudhary et al. 2020). Medihoney is one of the 
commercially available biopolymers and honey-based dressings and is composed of alginate containing at least 70\% active Leptospermum honey (Robson et al. 2009).

In view of the above, in this study we aimed to fabricate an antibacterial film as an effective wound dressing based on honey, BNC reinforced gelatin and aldehyde-modified GG. Finally, we developed an antibacterial film with good antibacterial activity, excellent biocompatibility, increased degradability, and improved mechanical properties, thus succeeding in providing a new wound dressing (H/BNC/Ge/AD-GG) with improved properties.

\section{Experimental Section}

\subsection{Materials}

Gelatin (from cold-water fish skin), guar gum, sodium periodate $\left(\mathrm{NaIO}_{4}\right)$, ethylene glycol, tetrazolium bromide (MTT), were obtained from Sigma-Aldrich. Trypsin-EDTA, fetal bovine serum (FBS), RPMI 1640 medium, and penicillin streptomycin (Pen/Strep) were supplied from Gibco. BNC was purchased from nano novin polymer Co. (Mazandaran Sci. \& Tech. Park, IRAN). Honey was collected from Bahraseman village, Jiroft, Iran. The Mueller-Hinton agar and dimethyl sulfoxide (DMSO) were obtained from Merck Chemicals Co (Germany). Fibroblast cells (NIH 3T3) were purchased from the institute Pasture (Iran). Pseudomonas aeruginosa (P. aeruginosa, Gram-positive) and Staphylococcus aureus (S. aureus, Gramnegative) bacteria were obtained from Persian Type Culture Collection (PTCC). All other solvents and reagents were of reagent grade.

\subsection{Synthesis of aldehyde-modified Guar gum (AD-GG)}

AD-GG was synthesized according to the previous study (1). Firstly, GG solution ( $0.25 \mathrm{wt} \%$ ) was prepared by dissolving 0.25 gram GG in $100 \mathrm{ml}$ deionized water at room temperature under stirring. After that, GG solution was oxidized by the addition of $3 \mathrm{~mL}$ sodium periodate $(0.1 \mathrm{~g} / \mathrm{mL})$ solution and the reaction was continued at this condition in the dark place. After 3 hours, the reaction was finished by the addition of $150 \mu \mathrm{L}$ ethylene glycol to eliminate the excess periodate. Finally, the obtained AD-GG solution was dialyzed with deionized water for 3 days using dialysis membrane (MWCO: 12-14000).

\subsection{Preparation of bacterial nanocellulose (BNC) reinforced gelatin-AD-GG films (BNC/Ge/AD-GG)}

The Ge powder was dissolved in deionized water at $50^{\circ} \mathrm{C}$ under stirring to obtain $4 \% \mathrm{w} / \mathrm{v}$ solution. Also, ethylene glycol, as a plasticizer was added to the Ge solution ( $40 \%$ dry weight of the $\mathrm{Ge}$ ). BNC water dispersions was prepared at $50 \% 25 \%$, and $12.5 \%$ concentration from dilutions of the original source of BNC suspension in deionized water under sonication. Then, BNC suspensions with the predetermined amounts ( $0.5 \mathrm{ml}$ from the original source and each prepared dispersion of BNC suspension) were separately added to the Ge solution and stirred at $40{ }^{\circ} \mathrm{C}$ for $15 \mathrm{~min}$. Finally, the films were prepared by blending the BNC reinforced Ge and AD-GG solutions with the ratio of 1:2 respectively (with total volume 
of $15 \mathrm{ml}$ ) and were poured into petri dishes to dry at the room temperature for 48 hours. Table 1 shows the formulations of the prepared different sample films.

Table 1: Different formulations for the preparation of sample films.

\begin{tabular}{|c|c|c|c|c|}
\hline $\begin{array}{l}\text { Film } \\
\text { sample }\end{array}$ & $\begin{array}{l}\text { Ratio of Ge } \\
\text { solution }\end{array}$ & Ratio of AD-GG & solution & BNC suspensions \\
\hline$A$ & 1 & 2 & & - \\
\hline \multirow[t]{2}{*}{ B } & 1 & 2 & & $0.5 \mathrm{ml}$ (original source) \\
\hline & & & & $0.5 \mathrm{ml}$ (50\% dispersion) \\
\hline \multirow[t]{2}{*}{ C } & 1 & 2 & & \\
\hline & & & & $0.5 \mathrm{ml}$ (25\% dispersion) \\
\hline D & 1 & 2 & & $\begin{array}{l}0.5 \mathrm{ml}(12.5 \% \\
\text { dispersion) }\end{array}$ \\
\hline E & 1 & 2 & & \\
\hline
\end{tabular}

\subsection{Preparation of honey loaded BNC reinforced gelatin-AD-GG films (H/BNC/Ge/AD-GG)}

The honey loaded films were prepared according to the previous section; various concentrations of honey based on the \% w/v of the film volume $(5,10$, and 15$)$ were added to the BNC reinforced Ge and AD-GG blended solution. Based on the mechanical properties of the developed BNC/Ge/AD-GG films, sample D was chosen for the preparation of the H/BNC/Ge/AD-GG films. The H/BNC/Ge/AD-GG films were named based on their honey concentrations: $D_{5}, D_{10}$, and $D_{15}$.

\subsection{Characterization of the fabricated films}

\subsubsection{Fourier transform infrared Spectrometer (FTIR)}


The samples chemical structures were determined using FTIR spectroscopy (Bruker-Tensor 27) at the wavenumber range of $400-4000 \mathrm{~cm}^{-1}$.

\subsubsection{Thermogravimetric analysis (TGA)}

To assess the thermal stability and decomposition temperature of the samples, TGA was carried out by TGA instrument (LINSEIS SPA PT 1600 device, Germany) from $25^{\circ} \mathrm{C}$ to $700^{\circ} \mathrm{C}$, under a nitrogen atmosphere flow.

\subsubsection{Mechanical behaviors of the fabricated films}

The mechanical behaviors of the fabricated films were investigated by tensile analyzer (SANTAM Machine, Iran) according to the guidelines established by ASTM. Briefly, the films were cut into the dumbbell-shaped (with $5.4 \times 3 \mathrm{~mm}$ sizes) and placed between two grips; the test speed was set at 10 $\mathrm{mm} / \mathrm{min}$.

\subsubsection{Morphology of the fabricated films}

The surface morphology of the obtained films was assessed by scanning electron microscopy (SEM, TESCAN, MIRA3). For this purpose, the films were sputter-coated with a gold layer and the images were captured.

\subsubsection{Swelling behavior of the fabricated films}

The swelling behavior of the prepared films were evaluated by incubation of them in PBS at $37^{\circ} \mathrm{C}$. All the dried films were weighted and immersed in PBS ( $\mathrm{pH}:$ 7.4). After $24 \mathrm{~h}$, the swelled films were taken out from the PBS, their excess surface liquid was removed by filter paper, and weighted. The swelling ratio of the samples were calculated by the following equation, where $W_{d}$ and $W_{s}$ represent the initial dry and final swelled weight of the films, respectively:

\section{Swelling ratio $=\frac{W s-W d}{W d}$}

\subsubsection{Degradation of the fabricated films}

To investigate the in vitro degradation behavior of the fabricated films, their weight loss was assessed after predetermined times incubation in PBS at $37^{\circ} \mathrm{C}$. For this purpose, the films were weighted and incubated in PBS ( $\mathrm{pH}:$ 7.4). At the predetermined times, the samples removed from the PBS, air-dried, and weighed. The degradation percentage of the various films was calculated from the following equation: where $W_{i}$ and $W_{f}$ represents the initial dry weight and final weight of the sample at the predetermined time. 


\section{Degradation $\%=\frac{W i-W f}{W i} \times 100$}

\subsubsection{Antibacterial study}

The antibacterial capacity of the fabricated films was evaluated by disk diffusion manner on agar plate against Staphylococcus aureus (S. aureus as gram-positive) and Escherichia coli (E. coli as gramnegative) bacteria. Briefly, the optimal film and the film containing honey were cut into the circular pieces with $10 \mathrm{~mm}$ diameter, UV light sterilized, placed to Muller Hinton Agar, which was cultured with $10^{6}$ $\mathrm{CFU} / \mathrm{mL}$ of bacterial suspension, and incubated overnight at $37^{\circ} \mathrm{C}$. The bacterial growth inhibition was assessed by diameters of the inhibition zones.

\subsubsection{Cell viability and proliferation assays}

To consider the biocompatibility of the films, MTT assay was carried out using NIH-3T3 fibroblast cells (Yavari Maroufi and Ghorbani 2021). NIH-3T3 fibroblast cells were cultured in RPMI-1640 medium containing $10 \% \mathrm{FBS}$ and $1 \%$ Pen/Strep at $37^{\circ} \mathrm{C}$ with $5 \% \mathrm{CO}_{2}$. After adequate cellular confluency, the biocompatibility evaluations were fulfilled. In brief, the fabricated films were cut into the small pieces and sterilized under UV light for $1 \mathrm{~h}$. The films were placed into the cell culture plate and the cell suspension with density of 5000 cells were added to each well. At the predetermined times $(1,3$, and 5 days after seeding), the medium was taken out, $3 \mathrm{mg} / \mathrm{mL}$ of MTT solution (in PBS) was added to each well, and incubated for $4 \mathrm{~h}$ at $37^{\circ} \mathrm{C}$. The MTT solution was removed and DMSO added to dissolve formazan crystals formed inside cells. Finally, the optical density (OD) of the produced violet formazan crystals was determined at $570 \mathrm{~nm}$ using spectrophotometer plate reader (Awareness Technologies Stat Fax 2100 Microplate Reader).

\subsubsection{Cell attachment study by SEM}

For evaluating the NIH-3T3 fibroblast cells attachment on the fabricated films, the fabricated samples were cut into the small pieces and sterilized under UV light. Cells were cultured on each film according to the previous section. After 3 days of cell seeding, following process was used to fix cells on the films: firstly, the medium was removed, films containing cells were washed with PBS, fixed with glutaraldehyde solution ( $4 \%$ ), dehydrated by serial ethanol solutions $(50 \%, 60 \%, 70 \%, 80 \%, 90 \%$, and $100 \%)$, and finally cells were visualized by SEM imaging.

\subsubsection{Statistical analysis}

Values were reported as mean \pm SD. Statistical differences $(P<0.05)$ were detected by One-way variance (ANOVA) test by using GraphPad Prism software.

\section{Results And Discussions}

\subsection{Morphological characterization of hydrogels}


In this study, we fabricated antibacterial films based on BNC reinforced with Ge/AD-GG containing honey. Fig. 1 shows the SEM images of the BNC/Ge/AD-GG films without and with $15 \%$ of honey. The developed films have revealed a uniform surface morphology. Moreover, the honey incorporation caused the formation of films with some thicker diameters which related to the variation in viscosity of polymer solution via the incorporation of honey.

\subsection{FTIR}

The spectra of honey, Ge, pure GG, and AD-GG are revealed in Fig. 2a, b, c, and d, respectively. The pure honey spectrum appeared peaks at $3360 \mathrm{~cm}^{-1}$ and $2935 \mathrm{~cm}^{-1}$, which were related to the $\mathrm{O}-\mathrm{H}$ and $\mathrm{C}-\mathrm{H}$ stretching of carboxylic acid groups, respectively. The detected bonds at $1650 \mathrm{~cm}^{-1}$ and $920 \mathrm{~cm}^{-1}$ were found to be related to the $\mathrm{C}=\mathrm{O}$ bonds stretching and $\mathrm{C}-\mathrm{H}$ bending of carbohydrate groups, respectively. The pure Ge FT-IR spectrum indicates the typical specific amide bands of proteins. The characterization absorption bond at $3400 \mathrm{~cm}^{-1}$ is represented to the $\mathrm{O}-\mathrm{H}$ and $\mathrm{N}-\mathrm{H}$ stretching vibration. The $\mathrm{C}-\mathrm{H}$ bonds stretching vibration was revealed at $2930 \mathrm{~cm}^{-1}$. The pure GG spectrum appeared absorption bonds at $3350 \mathrm{~cm}^{-1}$ and $2910 \mathrm{~cm}^{-1}$, which were represented to the $\mathrm{O}-\mathrm{H}$ and $\mathrm{C}-\mathrm{H}$ stretching, respectively. The absorption peak at $1124 \mathrm{~cm}^{-1}$ was found to be assigned to the $\mathrm{C}-\mathrm{O}$ bonds stretching. The aldehyde agents formation through the oxidation process of $G G$ and its conversion to AD-GG led to the two absorption peaks reveals at $\sim 1740 \mathrm{~cm}^{-1}$ and $889 \mathrm{~cm}^{-1}$ in FTIR spectrum. Besides, the FTIR spectra of pure BNC, Ge/AD-GG, BNC/Ge/AD-GG, and H/BNC/Ge/AD-GG were revealed in Fig. 3a, b, c, and d, respectively. For pure BNC, a broad characteristic bond at $3400 \mathrm{~cm}^{-1}$ and $2940 \mathrm{~cm}^{-1}$ were attributed to O-H and aliphatic $\mathrm{C}-\mathrm{H}$ stretching vibration, respectively. Another intense peak located at $1600 \mathrm{~cm}^{-1}$ was related to C-O-C stretching vibration. To verify the covalent interaction among the $\mathrm{NH}_{2}$ of $\mathrm{Ge}$ and the aldehyde agents of AD-GG, the spectrum of optimum Ge/AD-GG hydrogel (Ge/AD-GG 1:2) demonstrated an absorption bond at $1682 \mathrm{~cm}^{-1}$, which can be related to the newly created amide groups (Maroufi et al. 2021). For the FTIR spectra of BNC/Ge/AD-GG and H/BNC/Ge/AD-GG films, all characteristic peaks of $\mathrm{BNC}$ remained to be present, moreover, some additional peaks appeared in the spectrum from the characteristic groups of Ge, honey, and AD-GG. Moreover, the revealed some shifted the wavenumber and intensity of absorption peaks are due to the impact of honey interactions with BNC/Ge/AD-GG films.

\subsection{TGA analysis}

The TGA thermograms of the pure Ge, GG, Ge/AD-GG, BNC/Ge/AD-GG, and H/BNC/Ge/AD-GG were specified in Fig. 4. For all samples, as can realize from these thermograms, the first stage of weight loss $(25-150 \circ C)$ was assigned to the loss of moisture and free water content adsorbed in the prepared films. The second and main weight loss happened at around range of $250-350 \circ \mathrm{C}$ which is generally related to the polymer structure thermal decomposition as well as the degradation of the honey components followed by honey contents carbonization. The covalent cross-links presence in the structure of Ge/ADGG hydrogel between dialdehyde groups of AD-GG and amine groups of Ge has led to thermal durability. 


\subsection{Mechanical property}

The tensile stress behavior of developed films with BNC and with varying ratios of Honey $5 \%, 10 \%$, and $15 \%$ are shown in Fig. 5 . The good strength of developed films along with the presence of DAGG, is owing to the cross-linking between the amine groups of Ge and dialdehyde groups DAGG via a covalent bond. The prepared films with BNC incorporation showed fewer mechanical properties (Fig. 5A). Generally, BC is regarded as lacking elastic properties. As a result, the honey incorporation in developed films led to improved mechanical strength properties (Fig. 5B). Owing to the creation of more interpolymer bonds and enhanced physical cross-linking density via the honey addition, the hydrogel mechanical strength was improved noticeably (Ghorbani et al. 2021).

\subsection{Swelling studies}

The swelling profile of the prepared BNC/Ge/AD-GG films without (control) and with different honey concentrations of $5 \%, 10 \%$, and $15 \%$ are revealed in Fig. 6 . It was detected that although the prepared neat BNC/Ge/AD-GG films were revealed a high water absorption capacity. But, as detected in Fig.6, adding and increasing the honey concentration within the BNC/Ge/AD-GG films reduced its swelling capability. Based on the literature review, honey is recognized for its great water uptake capability and high water solubility (Mohd Zohdi et al. 2012). Such high water solubility results in increasing the degradation degrees of films and so losing their compacted porous structure that can maintain water. So, this finally affects considerably reduction in swelling capacity. This was confirmed in the very low swelling abilities of the BNC/Ge/AD-GG films with $15 \%$ of honey after $5 \mathrm{~h}$.

\subsection{In vitro degradation study}

The degradation behavior of the developed films following the enhancing of honey concentration was studied for 24 and $48 \mathrm{~h}$. As revealed in Fig. 7, via increasing the concentration of honey inside $\mathrm{BNC} / \mathrm{Ge} / \mathrm{AD}-\mathrm{GG}$ films, the improved degradation ability was detected after incubation in PBS at $37 \circ \mathrm{C}$ for about $48 \mathrm{~h}$. This can be attributed to the great water solubility of honey. Therefore, in the developed $\mathrm{BNC} / \mathrm{Ge} / \mathrm{AD}-\mathrm{GG}$ films containing a higher concentration of honey (15\%), the degradation rate improvement was illustrated.

\subsection{In vitro biocompatibility study}

In this study, comparing the pure films as control, the viability of the $3 T 3$ cells treated with BNC/Ge/ADGG films after 1,3 , and 5 days was tested via the WST1 assay. Fig. 8 revealed the cell viability of neat $\mathrm{BNC} / \mathrm{Ge} / \mathrm{AD}-\mathrm{GG}$ films and BNC/Ge/AD-GG with different content of honey $(5,10$, and $15 \mathrm{wt} \%)$ near $100 \%$ and confirmed good viability with increasing the weight addition of honey, showing that these obtained films are nontoxic and have excellent biocompatibility.

\subsection{Proliferation Test}


The potential of prepared films to support the attachment, growth, and cell proliferation is critical for tissue engineering applications. Fig. 9 revealed the NIH 3T3 fibroblast cells adhesion and penetration on $\mathrm{BNC} / \mathrm{Ge} / \mathrm{AD}-\mathrm{GG}$ films without and with various content of honey $(5 \%, 10 \%$, and $15 \mathrm{wt} \%)$ via SEM technique after culture for overnight. As shown in this Figure, the fibroblast cells were attached properly on the BNC/Ge/AD-GG films surface that revealed the fine interaction between the prepared film and cells. The cell growth behavior of BNC/Ge/AD-GG films showed improved cell adhesion with the $15 \mathrm{wt} \%$ of honey. So, according to the previous investigations [53], the incorporation of honey into the scaffolds may increase signals and endorsing cellular adhesion and proliferation. These obtained results confirmed that the developed H/BNC/Ge/AD-GG film is suitable for adhesion, growth, and cell proliferation, and has no cytotoxicity effect on fibroblast cells.

\subsection{Antimicrobial activity}

Fig. 10 and Table 2 show the inhibition activity against E. coli (Gram-negative) and S. aureus (Grampositive) bacteria for the blank films and honey incorporation in BNC/Ge/AD-GG film. The blank films as the control group represented no inhibition activity against selected bacteria. The highest inhibition zones were detected by BNC/Ge/AD-GG films with $15 \%$ of honey which those values were $13.0 \pm 0.1 \mathrm{~mm}$ (against S. aureus) and $15.0 \pm 1.0 \mathrm{~mm}$ (against E. coli). The antibacterial property of honey is represented by the high sugar content, acidity as well as ability for producing hydrogen peroxide. Hence, the honey incorporated BNC/Ge/AD-GG films revealed inhibition zones against selected bacteria. Related to similar previous reports [49], it could be noted that via increasing the honey concentration, the inhibition zone values were increased against both selected bacteria. Accordingly, the highest inhibition zones were achieved by developed films containing $15 \mathrm{wt} \%$ of honey.

Table 2. Inhibition zones $(\mathrm{cm})$ of the samples toward different bacteria.

\begin{tabular}{|llll|}
\hline \multicolumn{2}{|l|}{ Bacteria } & E. coli & S. aureus \\
\hline Entry & Sample & & \\
\hline a,b & Blank films & 0 & 0 \\
\hline c,d & Films with $15 \mathrm{wt} \%$ of honey & $15.0 \pm 1.0$ & $13.0 \pm 0.1$ \\
\hline
\end{tabular}

\section{Conclusion}

This paper describes a novel method for creating a high-yield antibacterial film using honey-infused BNC reinforced gelatin/aldehyde-modified Guar gum (H/BNC/Ge/AD-GG). Honey is a natural wound healer that has been reintroduced to clinical ulcer treatment due to its potent antibacterial properties. Various methodologies were used to investigate the physicochemical and biological aspects of successful produced films with and without honey. Honey content had a noticeable effect on the swelling behavior 
of hydrogel films. As a result, films containing $5 \%$ honey showed the most swelling, whereas films containing $15 \%$ honey showed the least swelling. The produced films demonstrated significant antibacterial efficacy against gram-positive and gram-negative bacteria, as well as cytocompatibility with human skin fibroblast cell lines. In addition, increased honey concentration resulted in improved mechanical properties, great cell adhesion, growth, and proliferation. Accordingly, the produced $\mathrm{H} / \mathrm{BNC} / \mathrm{Ge} / \mathrm{AD}-\mathrm{GG}$ films appear to have good promise as an antibacterial dressing for wound healing.

\section{Declarations}

\section{Ethics approval}

The study procedure was approved by the Ethical Committee of Tabriz University of Medical Science (Approval ID: IR. TBZMED.VCR.REC.1398.443).

\section{Conflicts of interest/Competing interests}

Not applicable.

\section{Acknowledgments}

The authors thank Department of Medical Nanotechnology, Faculty of Advanced Medical Sciences, Tabriz University of Medical Sciences for all supports provided Funding (Grant Number:64692).

\section{References}

1. Abou Zekry SS, Abdellatif A, Azzazy HME (2020) Fabrication of pomegranate/honey nanofibers for use as antibacterial wound dressings. Wound Med 28:. https://doi.org/10.1016/j.wndm.2020.100181

2. Alibolandi M, Bagheri E, Mohammadi M, et al (2021) Biopolymer-Based Hydrogel Wound Dressing. In: Modeling and Control of Drug Delivery Systems

3. Asadi N, Pazoki-Toroudi H, Del Bakhshayesh AR, et al (2021) Multifunctional hydrogels for wound healing: Special focus on biomacromolecular based hydrogels. Int. J. Biol. Macromol. 170

4. Bajpai A, Raj V (2021) Hydrophobically modified guar gum films for wound dressing. Polym Bull 78:. https://doi.org/10.1007/s00289-020-03302-4

5. Bandyopadhyay S, Saha N, Brodnjak UV, Sáha P (2019) Bacterial cellulose and guar gum based modified PVP-CMC hydrogel films: Characterized for packaging fresh berries. Food Packag Shelf Life 22:. https://doi.org/10.1016/j.fpsl.2019.100402

6. Banegas RS, Zornio CF, De Borges AMG, et al (2013) Preparation, characterization and properties of films obtained from cross-linked guar gum. Polimeros 23:.

https://doi.org/10.4322/polimeros.2013.082 
7. Bielecki S, Kalinowska H, Krystynowicz A, et al (2016) Wound dressings and cosmetic materials from bacterial nanocellulose. In: Bacterial NanoCellulose: A Sophisticated Multifunctional Material

8. Bierhalz ACK, Moraes ÂM (2016) Tuning the properties of alginate-chitosan membranes by varying the viscosity and the proportions of polymers. J Appl Polym Sci 133:.

https://doi.org/10.1002/app.44216

9. Bombaldi de Souza RF, Bombaldi de Souza FC, Bierhalz ACK, et al (2020) Biopolymer-based films and membranes as wound dressings. In: Biopolymer Membranes and Films

10. Ceylan S (2021) Propolis loaded and genipin-crosslinked PVA/chitosan membranes; characterization properties and cytocompatibility/genotoxicity response for wound dressing applications. Int J Biol Macromol 181:. https://doi.org/10.1016/j.jibiomac.2021.05.069

11. Chang W-H, Chang Y, Lai P-H, Sung H-W (2003) A genipin-crosslinked gelatin membrane as wounddressing material: in vitro and in vivo studies. J Biomater Sci Polym Ed 14:481-495. https://doi.org/10.1163/156856203766652084

12. Chaudhary A, Bag S, Banerjee P, Chatterjee J (2020) Wound healing efficacy of Jamun honey in diabetic mice model through reepithelialization, collagen deposition and angiogenesis. $\mathrm{J}$ Tradit Complement Med 10:. https://doi.org/10.1016/j.jtcme.2019.10.002

13. Chen J, Liu Z, Chen M, et al (2016) Electrospun Gelatin Fibers with a Multiple Release of Antibiotics Accelerate Dermal Regeneration in Infected Deep Burns. Macromol Biosci. https://doi.org/10.1002/mabi.201600108

14. Chen Y, Lu W, Guo Y, et al (2019) Electrospun gelatin fibers surface loaded ZnO particles as a potential biodegradable antibacterial wound dressing. Nanomaterials 9:. https://doi.org/10.3390/nano9040525

15. Coviello T, Alhaique F, Dorigo A, et al (2007) Two galactomannans and scleroglucan as matrices for drug delivery: Preparation and release studies. Eur J Pharm Biopharm 66:. https://doi.org/10.1016/j.ejpb.2006.10.024

16. Das D, Ara T, Dutta S, Mukherjee A (2011) New water resistant biomaterial biocide film based on guar gum. Bioresour Technol 102:. https://doi.org/10.1016/j.biortech.2011.02.034

17. Das S, De A, Das B, et al (2021) Development of gum odina-gelatin based antimicrobial loaded biodegradable spongy scaffold: A promising wound care tool. J Appl Polym Sci 138:. https://doi.org/10.1002/app.50057

18. Daud H, Ghani A, Iqbal DN, et al (2021) Preparation and characterization of guar gum based biopolymeric hydrogels for controlled release of antihypertensive drug. Arab J Chem 14:. https://doi.org/10.1016/j.arabjc.2021.103111

19. Dissemond J, Gerber V, Kramer A, et al (2010) A practice-oriented recommendation for treatment of critically colonised and locally infected wounds using polihexanide. J Tissue Viability 19:. https://doi.org/10.1016/j.jtv.2010.06.002

20. Doozandeh Z, Saber-Samandari S, Khandan A (2020) Preparation of novel arabic gum-c6h9no biopolymer as a bedsore for wound care application. Acta Med Iran 58:. 
https://doi.org/10.18502/acta.v58i10.4915

21. dos Santos CA, dos Santos GR, Soeiro VS, et al (2018) Bacterial nanocellulose membranes combined with nisin: a strategy to prevent microbial growth. Cellulose 25:. https://doi.org/10.1007/s10570-0182010-1

22. Farzanfar S, kouzekonan GS, Mirjani R, Shekarchi B (2020) Vitamin B12-loaded polycaprolacton/gelatin nanofibrous scaffold as potential wound care material. Biomed Eng Lett 10:. https://doi.org/10.1007/s13534-020-00165-6

23. Fu L, Zhou P, Zhang S, Yang G (2013) Evaluation of bacterial nanocellulose-based uniform wound dressing for large area skin transplantation. Mater Sci Eng C 33:. https://doi.org/10.1016/j.msec.2013.03.026

24. Garcia-Orue I, Santos-Vizcaino E, Etxabide A, et al (2019) Development of bioinspired gelatin and gelatin/chitosan bilayer hydrofilms for wound healing. Pharmaceutics 11: https://doi.org/10.3390/pharmaceutics 11070314

25. George A, Shah PA, Shrivastav PS (2019) Guar gum: Versatile natural polymer for drug delivery applications. Eur. Polym. J. 112

26. Ghorbani M, Ramezani S, Rashidi MR (2021) Fabrication of honey-loaded ethylcellulose/gum tragacanth nanofibers as an effective antibacterial wound dressing. Colloids Surfaces $A$ Physicochem Eng Asp 621:. https://doi.org/10.1016/j.colsurfa.2021.126615

27. Ghosh Auddy R, Abdullah MF, Das S, et al (2013) New guar biopolymer silver nanocomposites for wound healing applications. Biomed Res Int 2013.. https://doi.org/10.1155/2013/912458

28. Ghosh SK, Das A, Basu A, et al (2018) Semi-interpenetrating hydrogels from carboxymethyl guar gum and gelatin for ciprofloxacin sustained release. Int J Biol Macromol 120:.

https://doi.org/10.1016/j.jibiomac.2018.09.212

29. Hsu LC, Peng BY, Chen MS, et al (2019) The potential of the stem cells composite hydrogel wound dressings for promoting wound healing and skin regeneration: In vitro and in vivo evaluation. $J$ Biomed Mater Res - Part B Appl Biomater 107:. https://doi.org/10.1002/jbm.b.34118

30. Ilkar Erdagi S, Asabuwa Ngwabebhoh F, Yildiz U (2020) Genipin crosslinked gelatin-diosgeninnanocellulose hydrogels for potential wound dressing and healing applications. Int J Biol Macromol 149:. https://doi.org/10.1016/j.ijbiomac.2020.01.279

31. Kanokpanont S, Damrongsakkul S, Ratanavaraporn J, Aramwit P (2012) An innovative bi-layered wound dressing made of silk and gelatin for accelerated wound healing. Int J Pharm 436: https://doi.org/10.1016/j.ijpharm.2012.06.046

32. Kavoosi G, Dadfar SMM, Purfard AM (2013) Mechanical, Physical, Antioxidant, and Antimicrobial Properties of Gelatin Films Incorporated with Thymol for Potential Use as Nano Wound Dressing. J Food Sci 78:. https://doi.org/10.1111/1750-3841.12015

33. Kenawy E, Omer AM, Tamer TM, et al (2019) Fabrication of biodegradable gelatin/chitosan/cinnamaldehyde crosslinked membranes for antibacterial wound dressing applications. Int J Biol Macromol 139:. https://doi.org/10.1016/j.ijbiomac.2019.07.191 
34. Khalil AT, Khan I, Ahmad K, et al (2014) Antibacterial activity of honey in north-west Pakistan against select human pathogens. J Tradit Chinese Med 34:. https://doi.org/10.1016/s0254-6272(14)60059-5

35. Kingley A, Tadej M, Colbourn A, et al (2009) Suprasorb ${ }^{\circledR} X+P H M B$ : Antimicrobial and HydroBalance action in a new wound dressing. Wounds UK 5

36. Kucharska M, Niekraszewicz A, Wiśniewska-Wrona M, Brzoza-Malczewska K (2008) Dressing sponges made of chitosan and chitosan-alginate fibrids. Fibres Text East Eur 16:

37. Li H, Wang M, Williams GR, et al (2016) Electrospun gelatin nanofibers loaded with vitamins $A$ and e as antibacterial wound dressing materials. RSC Adv 6:. https://doi.org/10.1039/c6ra05092a

38. Lin FS, Lee JJ, Lee AKX, et al (2021) Calcium silicate-activated gelatin methacrylate hydrogel for accelerating human dermal fibroblast proliferation and differentiation. Polymers (Basel) 13:. https://doi.org/10.3390/polym13010070

39. Maroufi LY, Tabibiazar M, Ghorbani M, Jahanban-Esfahlan A (2021) Fabrication and characterization of novel antibacterial chitosan/dialdehyde guar gum hydrogels containing pomegranate peel extract for active food packaging application. Int J Biol Macromol 187:. https://doi.org/10.1016/j.jibiomac.2021.07.126

40. Maver T, Hribernik S, Mohan T, et al (2015) Functional wound dressing materials with highly tunable drug release properties. RSC Adv 5:. https://doi.org/10.1039/c5ra11972c

41. McClements DJ, Gumus CE (2016) Natural emulsifiers - Biosurfactants, phospholipids, biopolymers, and colloidal particles: Molecular and physicochemical basis of functional performance. Adv. Colloid Interface Sci. 234

42. Mishra RK, Majeed ABA, Banthia AK (2011) Development and characterization of pectin/gelatin hydrogel membranes for wound dressing. Int J Plast Technol 15:. https://doi.org/10.1007/s12588011-9016-y

43. Mohd Zohdi R, Abu Bakar Zakaria Z, Yusof N, et al (2012) Gelam (Melaleuca spp.) honey-based hydrogel as burn wound dressing. Evidence-based Complement Altern Med 2012:. https://doi.org/10.1155/2012/843025

44. Moritz S, Wiegand C, Wesarg F, et al (2014) Active wound dressings based on bacterial nanocellulose as drug delivery system for octenidine. Int J Pharm 471:. https://doi.org/10.1016/j.ijpharm.2014.04.062

45. Morsy R, Hosny M, Reicha F, Elnimr T (2017) Developing a potential antibacterial long-term degradable electrospun gelatin-based composites mats for wound dressing applications. React Funct Polym 114:. https://doi.org/10.1016/j.reactfunctpolym.2017.03.001

46. Nezhad-Mokhtari P, Arsalani N, Ghorbani M, Hamishehkar H (2018) Development of biocompatible fluorescent gelatin nanocarriers for cell imaging and anticancer drug targeting. J Mater Sci 53:. https://doi.org/10.1007/s10853-018-2371-8

47. Nezhad-Mokhtari P, Arsalani N, Javanbakht S, Shaabani A (2019) Development of gelatin microsphere encapsulated $\mathrm{Cu}$-based metal-organic framework nanohybrid for the methotrexate delivery. J Drug Deliv Sci Technol 50:. https://doi.org/10.1016/j.jddst.2019.01.020 
48. Nezhad-Mokhtari P, Javanbakht S, Asadi N, et al (2021) Recent advances in honey-based hydrogels for wound healing applications: Towards natural therapeutics. J. Drug Deliv. Sci. Technol. 66

49. Obagi Z, Damiani G, Grada A, Falanga V (2019) Principles of wound dressings: A review. Surg. Technol. Int. 35

50. Pacheco MS, Kano GE, Paulo L de A, et al (2020) Silk fibroin/chitosan/alginate multilayer membranes as a system for controlled drug release in wound healing. Int J Biol Macromol 152: https://doi.org/10.1016/j.jibiomac.2020.02.140

51. Poonguzhali R, Khaleel Basha S, Sugantha Kumari V (2018) Fabrication of asymmetric nanostarch reinforced Chitosan/PVP membrane and its evaluation as an antibacterial patch for in vivo wound healing application. Int J Biol Macromol 114:. https://doi.org/10.1016/j.jbiomac.2018.03.092

52. Prabaharan M (2011) Prospective of guar gum and its derivatives as controlled drug delivery systems. Int. J. Biol. Macromol. 49

53. Prasetyo RH, Safitri E (2018) TOPICAL HONEY TO TREAT AN ABSCESS CAUSED BY STAPHYLOCOCCUS AUREUS: A CASE REPORT. Southeast Asian J Trop Med Public Health 49:

54. Rahmani Del Bakhshayesh A, Akbarzadeh A, Alihemmati A, et al (2020) Preparation and characterization of novel anti-inflammatory biological agents based on piroxicam-loaded poly- $\varepsilon$ caprolactone nano-particles for sustained NSAID delivery. Drug Deliv 27:. https://doi.org/10.1080/10717544.2020.1716881

55. Rahmani Del Bakhshayesh A, Annabi N, Khalilov R, et al (2018a) Recent advances on biomedical applications of scaffolds in wound healing and dermal tissue engineering. Artif. Cells, Nanomedicine Biotechnol. 46

56. Rahmani Del Bakhshayesh A, Mostafavi E, Alizadeh E, et al (2018b) Fabrication of ThreeDimensional Scaffolds Based on Nano-biomimetic Collagen Hybrid Constructs for Skin Tissue Engineering. ACS Omega 3:. https://doi.org/10.1021/acsomega.8b01219

57. Robson V, Dodd S, Thomas S (2009) Standardized antibacterial honey (Medihoney ${ }^{\mathrm{TM}}$ ) with standard therapy in wound care: Randomized clinical trial. J Adv Nurs 65:. https://doi.org/10.1111/j.13652648.2008.04923.x

58. Sahana TG, Rekha PD (2018) Biopolymers: Applications in wound healing and skin tissue engineering. Mol. Biol. Rep. 45

59. Samadian H, Zamiri S, Ehterami A, et al (2020) Electrospun cellulose acetate/gelatin nanofibrous wound dressing containing berberine for diabetic foot ulcer healing: in vitro and in vivo studies. Sci Rep 10:. https://doi.org/10.1038/s41598-020-65268-7

60. Suarato G, Bertorelli R, Athanassiou A (2018) Borrowing from nature: Biopolymers and biocomposites as smart wound care materials. Front. Bioeng. Biotechnol. 6

61. Taghipour YD, Hokmabad VR, Del Bakhshayesh AR, et al (2019) The Application of Hydrogels Based on Natural Polymers for Tissue Engineering. Curr Med Chem 27:.

https://doi.org/10.2174/0929867326666190711103956

Page 15/23 
62. Tan C, Wang J, Sun B (2021) Biopolymer-liposome hybrid systems for controlled delivery of bioactive compounds: Recent advances. Biotechnol. Adv. 48

63. Tanaka A, Nagate T, Matsuda $\mathrm{H}$ (2005) Acceleration of wound healing by gelatin film dressings with epidermal growth factor. J Vet Med Sci 67:. https://doi.org/10.1292/jvms.67.909

64. Tang $Y$, Lan X, Liang $C$, et al (2019) Honey loaded alginate/PVA nanofibrous membrane as potential bioactive wound dressing. Carbohydr Polym 219:. https://doi.org/10.1016/j.carbpol.2019.05.004

65. Tavakoli J, Tang Y (2017) Honey/PVA hybrid wound dressings with controlled release of antibioticsStructural, physico-mechanical and in-vitro biomedical studies. Mater Sci Eng C 77:. https://doi.org/10.1016/j.msec.2017.03.272

66. Thakur S, Chauhan GS, Ahn JH (2009) Synthesis of acryloyl guar gum and its hydrogel materials for use in the slow release of I-DOPA and I-tyrosine. Carbohydr Polym 76:.

https://doi.org/10.1016/j.carbpol.2008.11.012

67. Tottoli EM, Dorati R, Genta I, et al (2020) Skin wound healing process and new emerging technologies for skin wound care and regeneration. Pharmaceutics 12:1-30

68. Trinca RB, Westin CB, da Silva JAF, Moraes ÂM (2017) Electrospun multilayer chitosan scaffolds as potential wound dressings for skin lesions. Eur Polym J 88:

https://doi.org/10.1016/j.eurpolymj.2017.01.021

69. Wang T, Zhu XK, Xue XT, Wu DY (2012) Hydrogel sheets of chitosan, honey and gelatin as burn wound dressings. Carbohydr Polym 88.. https://doi.org/10.1016/j.carbpol.2011.11.069

70. Yaghoobi M, Nasrollahzadeh M, Asjadi F (2019) Modern Wound Dressings and their Application. J Shahid Sadoughi Univ Med Sci. https://doi.org/10.18502/ssu.v27i6.1599

71. Yavari Maroufi L, Ghorbani M (2021) Development of a Novel Antibacterial Hydrogel Scaffold Based on Guar Gum/Poly (methylvinylether-alt-maleic Acid) Containing Cinnamaldehyde-Loaded Chitosan Nanoparticles. J Polym Environ. https://doi.org/10.1007/s10924-021-02216-0

72. Ye S, Jiang L, Su C, et al (2019) Development of gelatin/bacterial cellulose composite sponges as potential natural wound dressings. Int. J. Biol. Macromol. 133:148-155

73. Yilmaz AC, Aygin D (2020) HONEY DRESSING IN WOUND TREATMENT: A SYSTEMATIC REVIEW. Complement. Ther. Med. 51

\section{Figures}




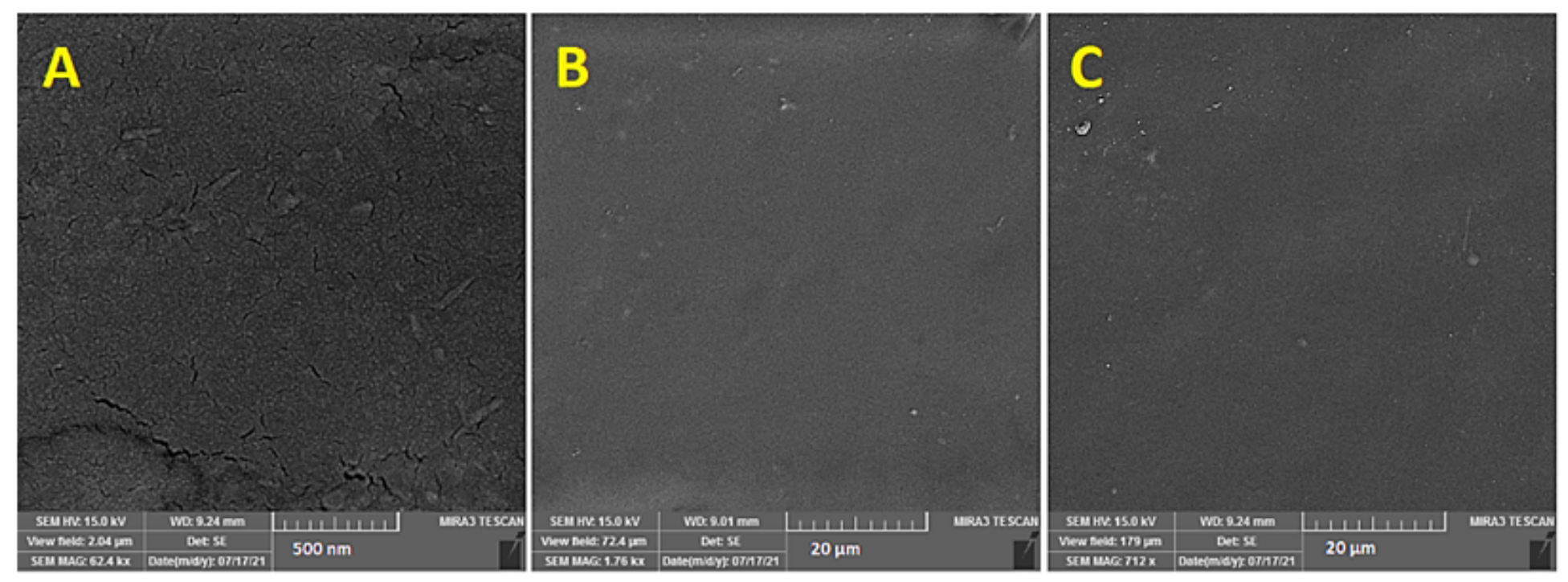

Figure 1

SEM images of BNC/Ge/AD-GG films without (A, B) and with $15 \%$ of honey (C). * BNC: Bacterial nanocellulose, H: Honey, Ge: Gelatin, GG: Guar gum, AD-GG: aldehyde-modified GG.

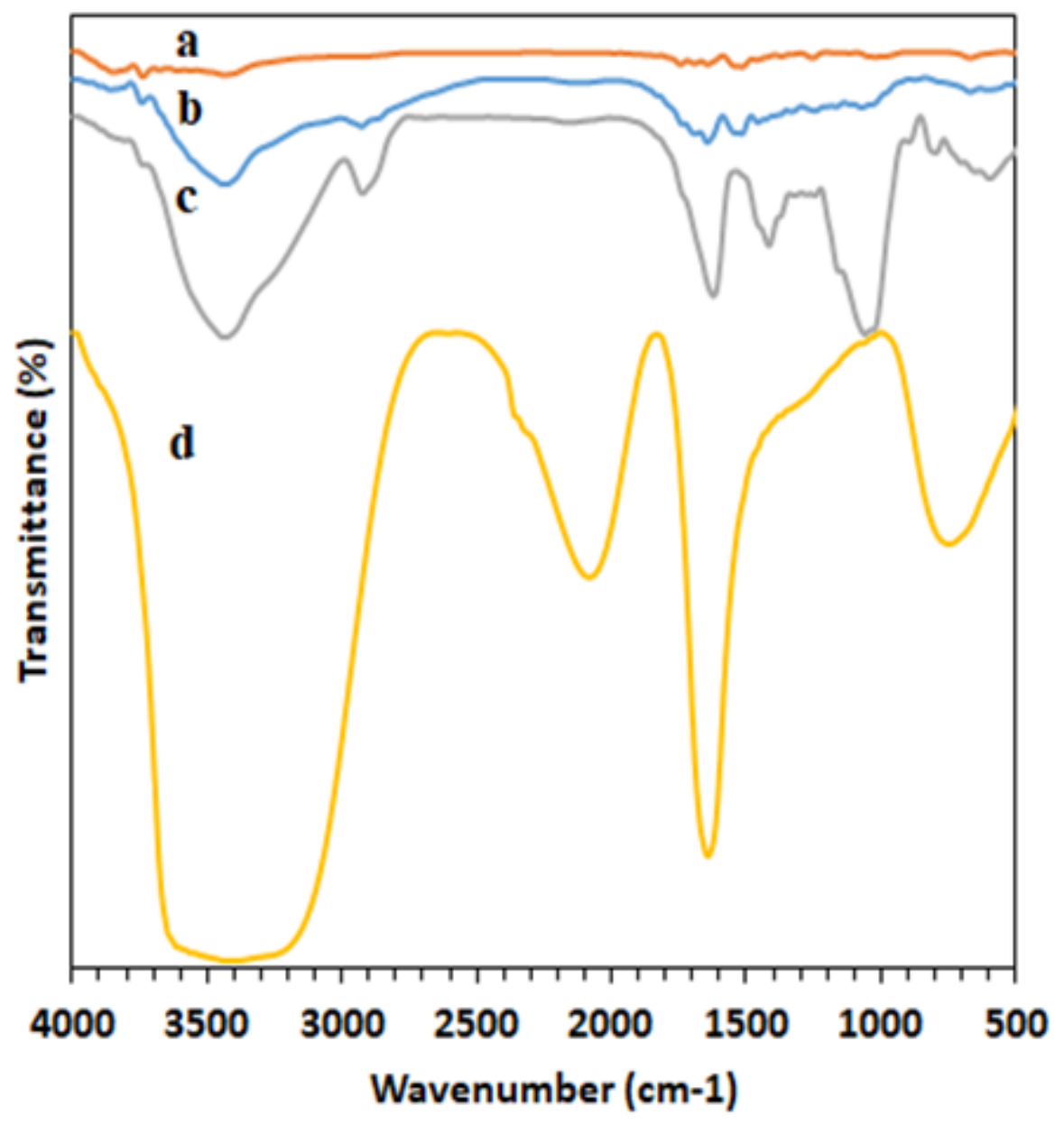

Figure 2 
Fourier transform infrared (FTIR) of pure H (a), pure Ge (b), pure GG (c), and AD-GG (d). H: Honey, Ge: Gelatin, GG: Guar gum, AD-GG: aldehyde-modified GG.

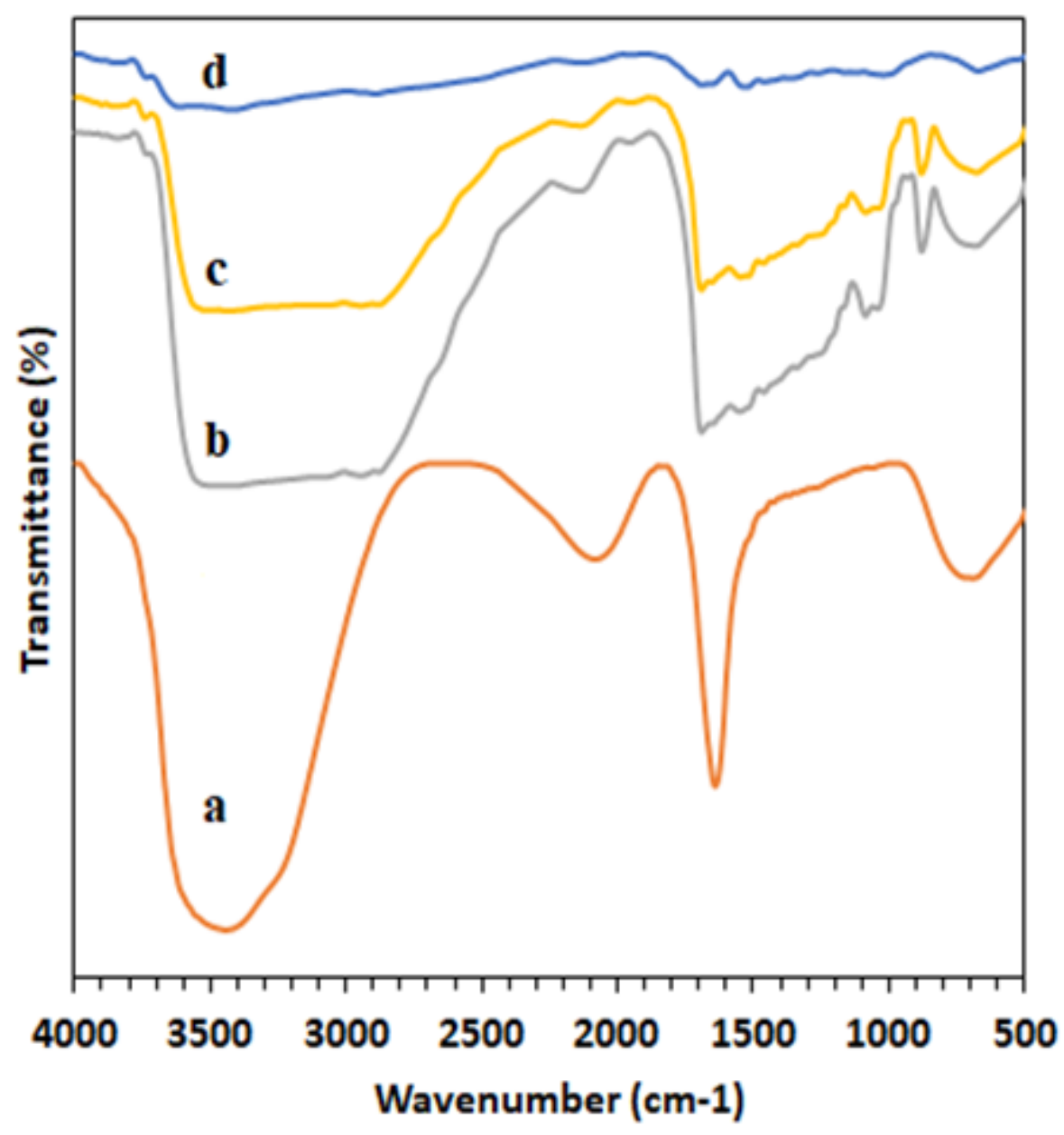

Figure 3

Fourier transform infrared (FTIR) of pure BNC (a), Ge/AD-GG (b), BNC/Ge/AD-GG (c), and H/BNC/Ge/ADGG (d). BNC: Bacterial nanocellulose, H: Honey, Ge: Gelatin, GG: Guar gum, AD-GG: aldehyde-modified GG. 


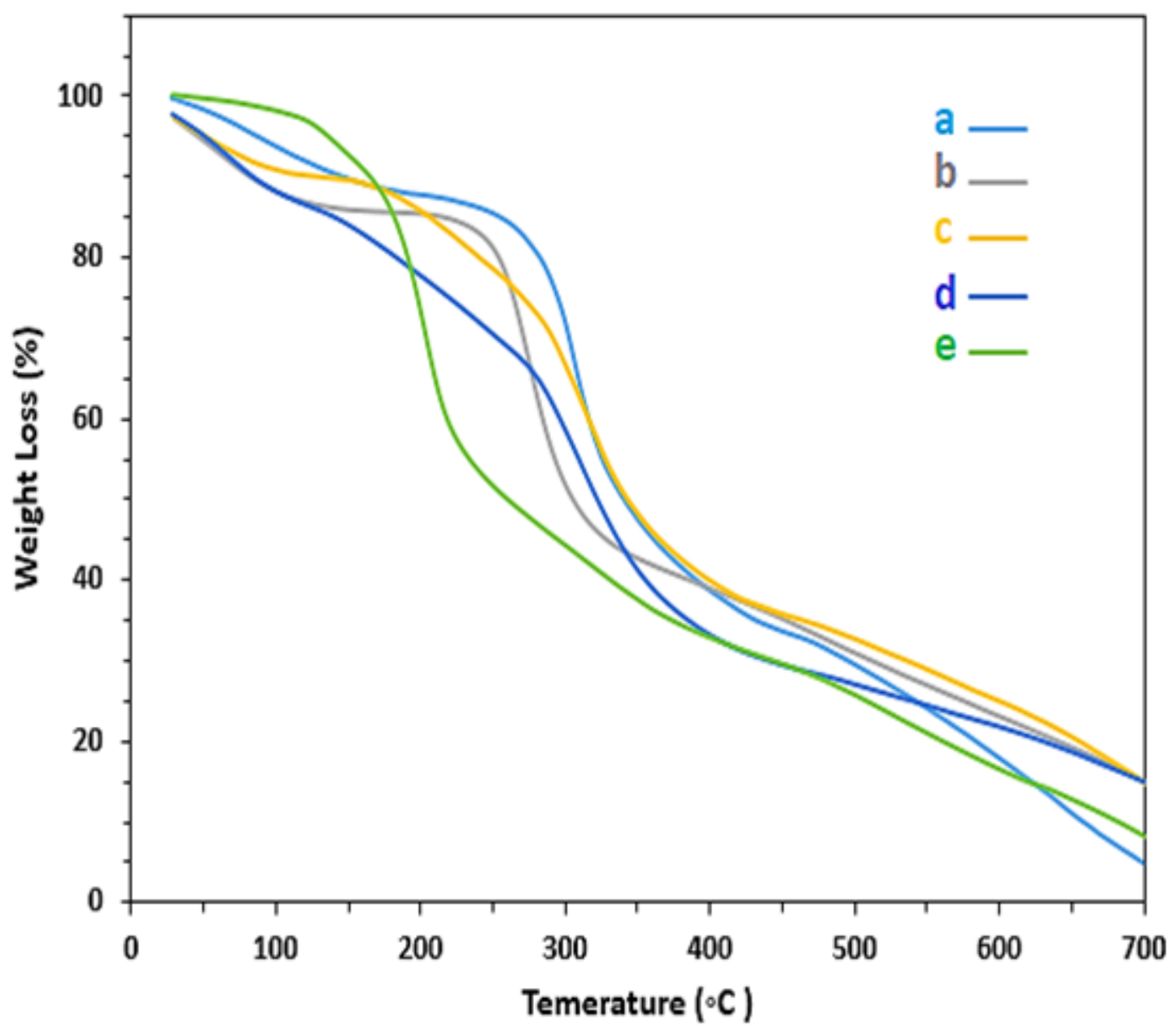

Figure 4

TGA curves of pure Ge (a), GG (b), Ge/AD-GG (c), BNC/Ge/AD-GG (d), and H/BNC/Ge/AD-GG (e). BNC: Bacterial nanocellulose, H: Honey, Ge: Gelatin, GG: Guar gum, AD-GG: aldehyde-modified GG. 

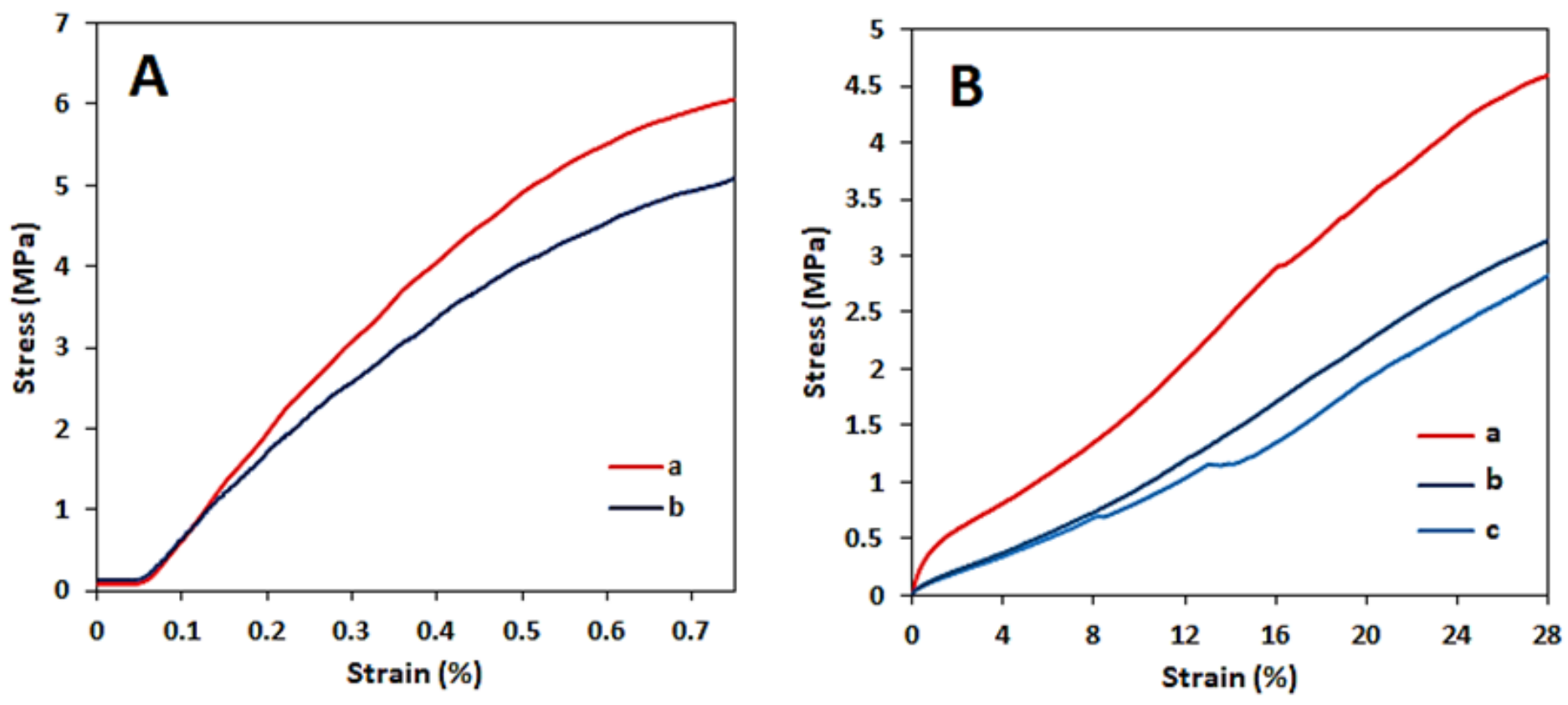

Figure 5

Typical stress-strain curves of Ge/AD-GG films without (a) and with BNC (b) (A), and the BNC/Ge/AD-GG films with various content of honey $15 \%$ (a), $10 \%$ (b), and $5 \%$ (c) (B). Results are mean \pm SD (n=3). * BNC: Bacterial nanocellulose, H: Honey, Ge: Gelatin, GG: Guar gum, AD-GG: aldehyde-modified GG.

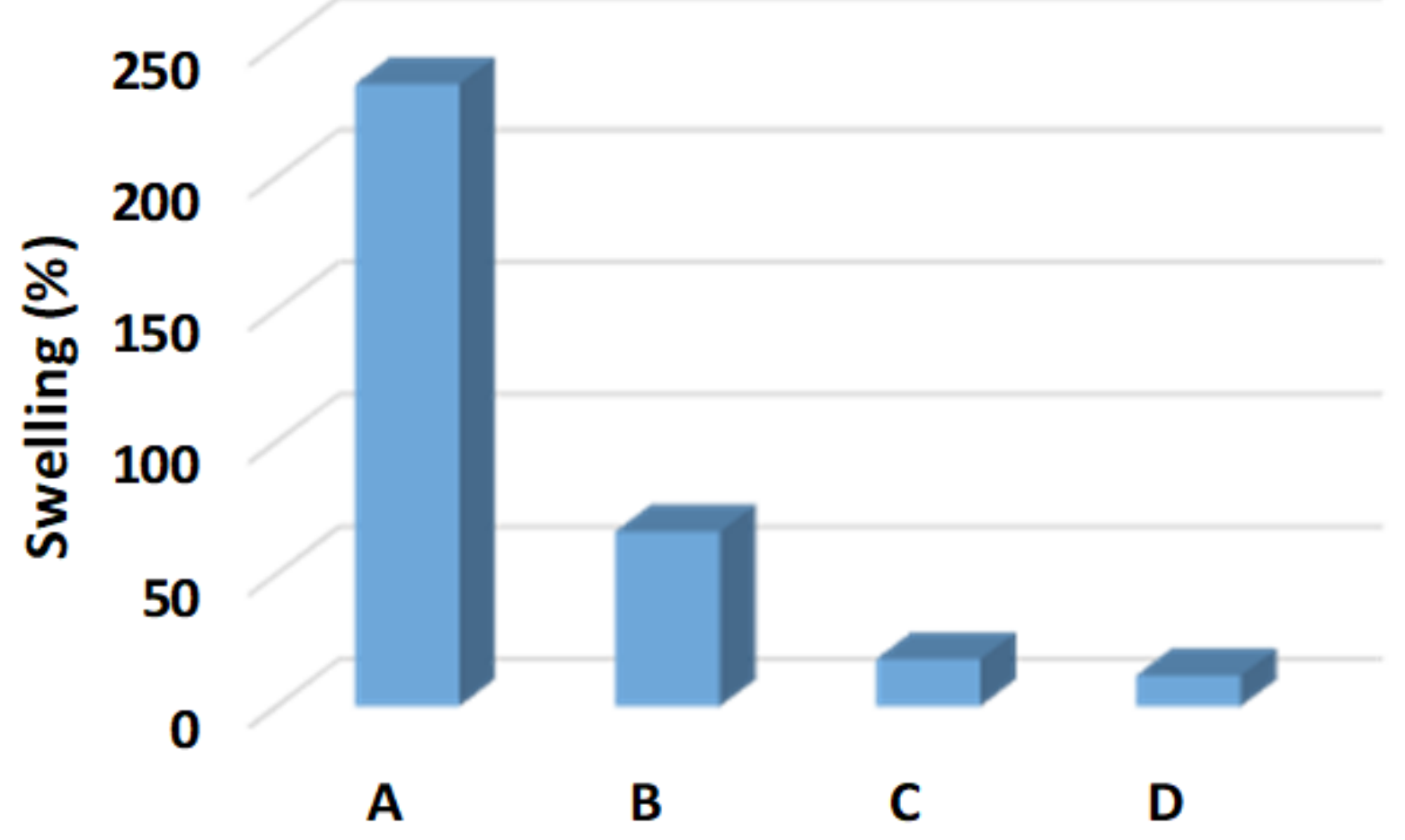

Figure 6 
The swelling ratio profiles of BNC/Ge/AD-GG films without (A) and with different content of honey $5 \%$ (B), $10 \%(C)$, and 15\% (D) after $5 \mathrm{~h}$. Results are mean \pm SD $(n=3)$. * BNC: Bacterial nanocellulose, $\mathrm{H}$ : Honey, Ge: Gelatin, GG: Guar gum, AD-GG: aldehyde-modified GG.

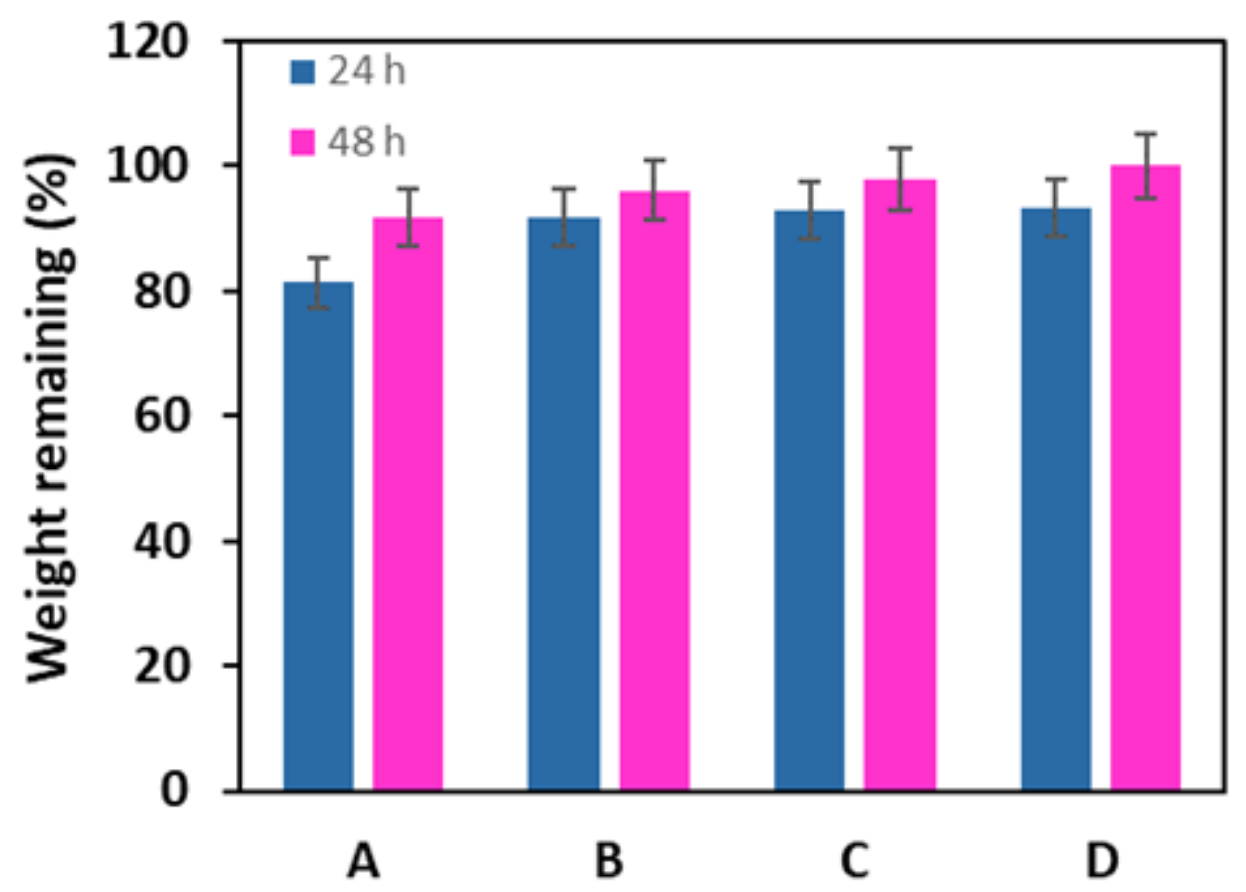

Figure 7

Degradation profile of BNC/Ge/AD-GG films without (A) and with different content of honey $5 \%(B), 10 \%$ (C), and 15\% (D) after $24 \mathrm{~h}$ and $48 \mathrm{~h}$. Results are mean $\pm \mathrm{SD}(\mathrm{n}=3)$. * BNC: Bacterial nanocellulose, $\mathrm{H}$ : Honey, Ge: Gelatin, GG: Guar gum, AD-GG: aldehyde-modified GG. 


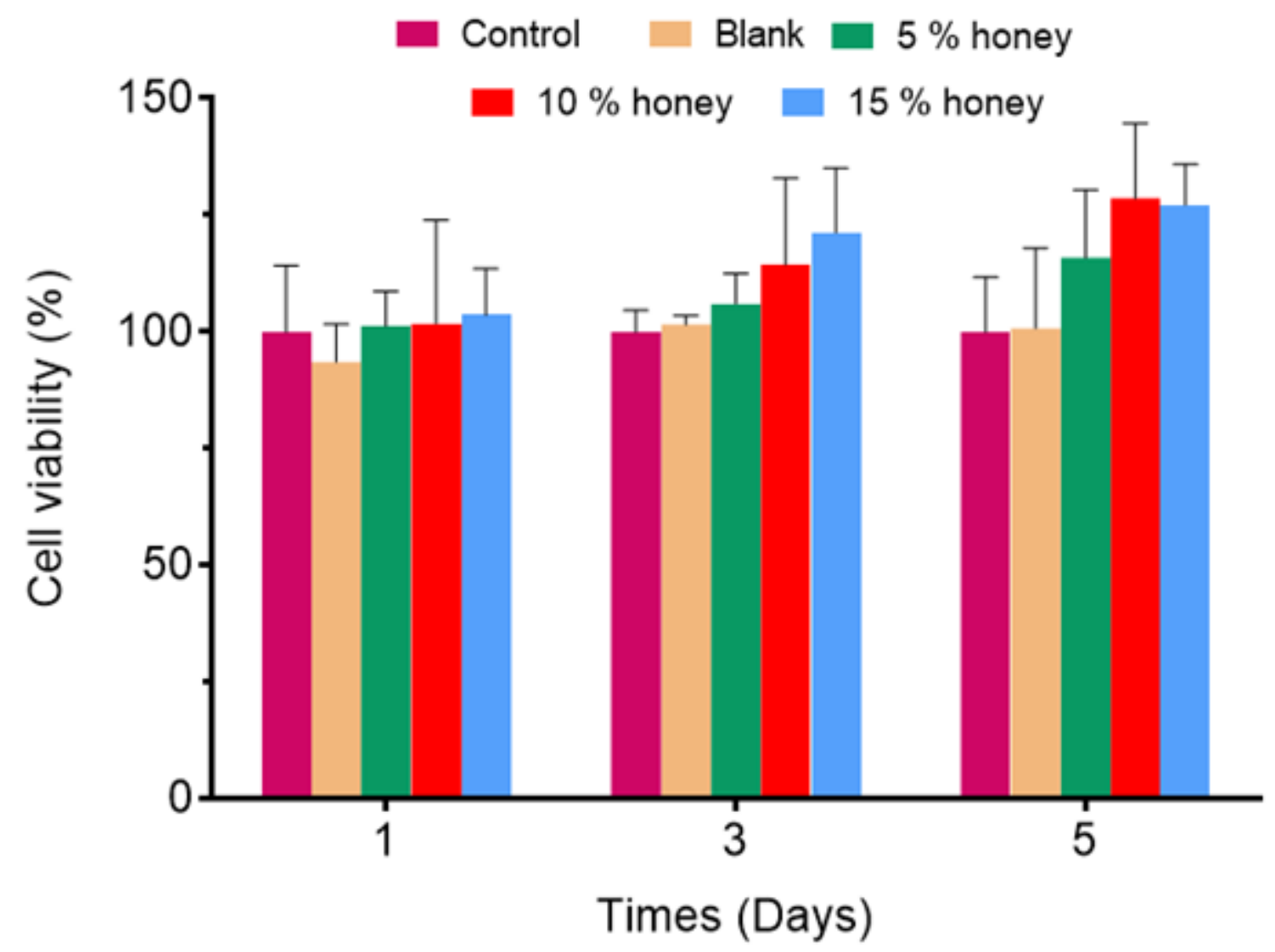

Figure 8

The biocompatibility test of BNC/Ge/AD-GG films without and with different content of honey $5 \%(B)$, $10 \%(C)$, and $15 \%(D)$. Results are mean \pm SD $(n=3)$. * BNC: Bacterial nanocellulose, H: Honey, Ge: Gelatin, GG: Guar gum, AD-GG: aldehyde-modified GG.
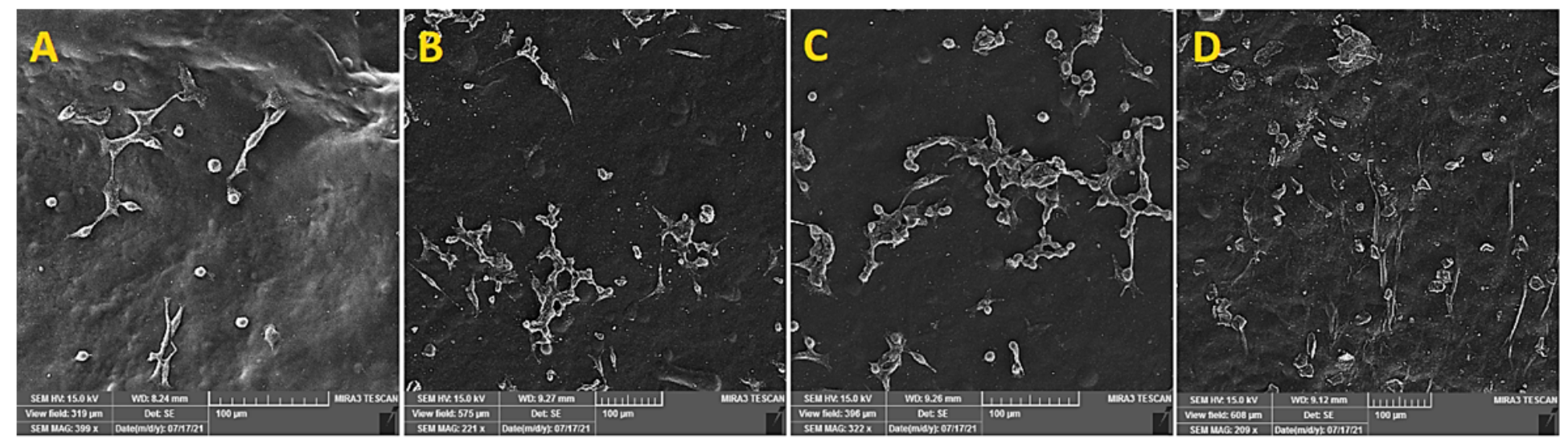

\section{Figure 9}

Cell viability of NIH 3 T3 fibroblast cells for BNC/Ge/AD-GG films without (A) and with different honey content $5 \%(B), 10 \%(C)$, and $15 \%(D)$. Results are mean \pm SD $(n=3)$. * BNC: Bacterial nanocellulose, $H$ : Honey, Ge: Gelatin, GG: Guar gum, AD-GG: aldehyde-modified GG. 

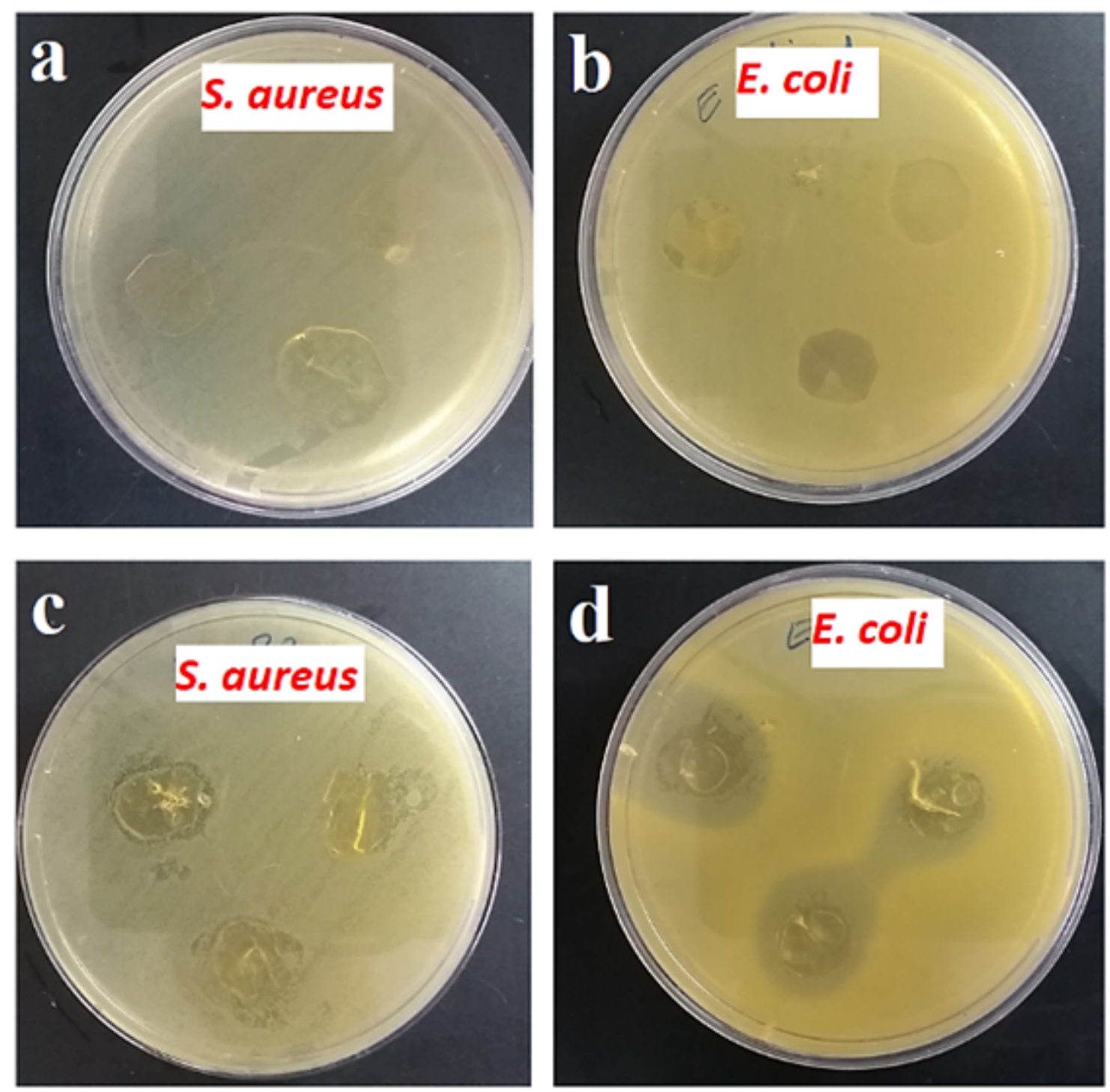

Figure 10

The antibacterial activity of blank BNC/Ge/AD-GG films $(a, b)$ and with $15 \mathrm{wt} \%$ of honey (H/BNC/Ge/ADGG films) (c, d) against S. aureus and E. coli bacteria. BNC: Bacterial nanocellulose, *H: Honey, Ge: Gelatin, GG: Guar gum, AD-GG: aldehyde-modified GG.

\section{Supplementary Files}

This is a list of supplementary files associated with this preprint. Click to download.

- GA.jpg 